\title{
High risk of dengue type 2 outbreak in French Polynesia, 2017
}

M Aubry ${ }^{1}$, Y Teissier ${ }^{12}$, M Mapotoeke ${ }^{3}$, A Teissier ${ }^{1}$, M Giard ${ }^{3}$, D Musso ${ }^{1}$, V Cao-Lormeau ${ }^{1}$

1. Unit of Emerging Infectious Diseases, Institut Louis Malardé, Papeete, Tahiti, French Polynesia

2. ED 474, Université Sorbonne Paris Cité, Paris, France

3. Direction de la Santé de la Polynésie française, Papeete, Tahiti, French Polynesia

Correspondence: Maite Aubry (maubry@ilm.pf)

In French Polynesia, the four serotypes of dengue virus (DENV-1 to -4) have caused 14 epidemics since the mid-1940s. From the end of 2016, an increasing number of Pacific Island Countries and Territories have reported DENV-2 outbreaks and in February 2017, DENV-2 infection was detected in French Polynesia in three travellers from Vanuatu. As DENV-2 has not been circulating in French Polynesia since December 2000, there is high risk for an outbreak to occur.

In February 2017, three travellers from Vanuatu were diagnosed with dengue virus serotype 2 (DENV-2) infection in French Polynesia (a French collectivity in the South Pacific). As DENV-2 has not been circulating in the country for ca 16 years, we discuss here the risk factors that could contribute in a near future to the re-emergence of this virus in French Polynesia and to subsequent dissemination to other, not yet affected, Pacific islands and continental countries having close links with European overseas countries and territories.

\section{Detection of imported cases of DENV-2 infections in French Polynesia}

A soccer contest involving participants from Fiji, New Caledonia, New Zealand, Papua New Guinea, Samoa, Solomon Islands and Vanuatu was organised in French Polynesia in February 2017. Because of the ongoing circulation of DENV-2 in several of these Pacific Island Countries and Territories (PICTs) (Figure 1) [1,2], surveillance measures were strengthened by the French Polynesia Direction of Health.

Participants who declared febrile illness after their arrival in French Polynesia were immediately examined by a medical practitioner, and a blood sample was collected and sent to the Institut Louis Malardé (Papeete, Tahiti, French Polynesia) for DENV diagnosis and DENV genotyping by real-time RT-PCR, using previously published oligonucleotide primers and probe [3]. Three serum samples received from participants from Vanuatu tested positive for DENV-2. Two additional serum samples collected from participants from Vanuatu, and four serum samples collected from participants from Papua New Guinea, tested negative for all four serotypes of DENV.

\section{Phylogenetic analysis}

The complete envelope gene of the DENV-2 strains isolated from the three participants was sequenced with the Abi 3500 genetic analyzer (Applied Biosystems, US), using primers D2/618V (5'-ACCAGAAGACATAGATTGTTGGTGC-3'), DEN-2F (5'- CAGGTTATGGCACTGTCACGA-3'), DEN-2C (5'-CCATCTGCAGCAACACCATCT-3'), D2RS2271 (5'-CCCATAGATTGCTCCGAAAAC-3') and D2/2578 (5'-TTACTGAGCGGATTCCACAGATGCC-3').

Phylogenetic analysis showed that the three DENV-2 strains imported to French Polynesia from Vanuatu (GenBank accession numbers: KY782125, KY782126 and $K Y 782127)$ belonged to the Cosmopolitan genotype, and were closely related to strains collected in 2014 in Tuvalu and Fiji, with percentages of homology of more than $99.7 \%$ (Figure 2).

\section{Background}

In French Polynesia, a French Overseas collectivity of ca 270,000 inhabitants in the south-east Pacific, the four serotypes of DENV have caused successive epidemics since the 1940s, and outbreaks due to Zika (ZIKV) and chikungunya (CHIKV) viruses have also been reported recently [4-10]. The epidemiology of DENV in French Polynesia, as in several other PICTs, is characterised by the long-term predominance of a single serotype; its transmission can persist in an endemic way during 4-5 years until the virus causes a new outbreak or is replaced by another serotype $[6,7,11,12]$. In contrast to DENV serotypes 1,3 and 4 that have caused several epidemics during the past 16 years (DENV-1 in 2001, 2006-07 and 2013-17; DENV-3 in 2013-14; and 


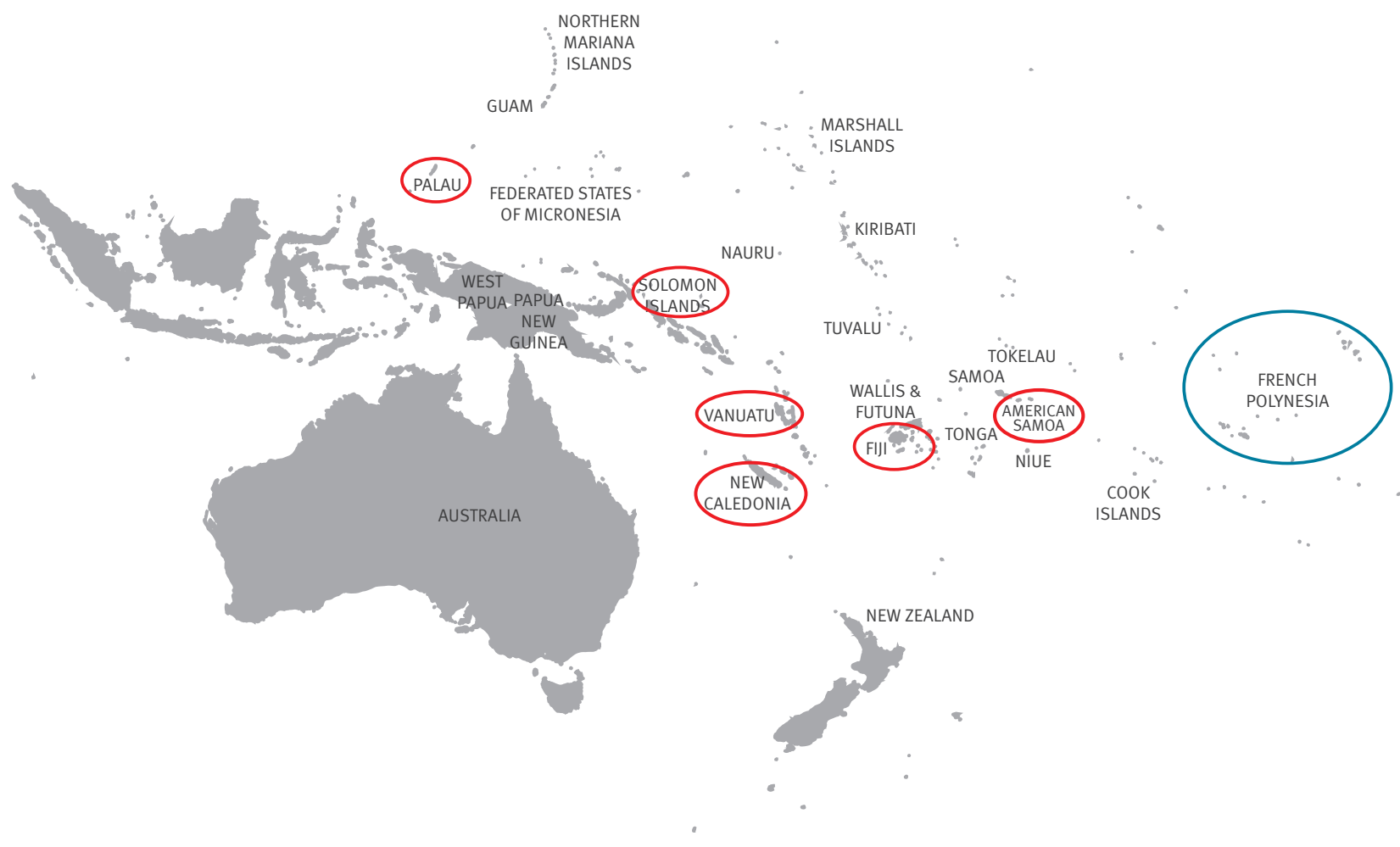

DENV: dengue virus.

Areas where DENV-2 epidemics have been recorded are surrounded by red circles. French Polynesia is indicated by a blue circle.

Source: [1,2]; map downloaded from: https://www.shutterstock.com/g/Armita.

DENV-4 in 2009) (Figure 3) $[4-10,13]$, the last DENV-2 outbreak occurred in 1996-97 [11] and the last report of autochthonous DENV-2 infection was in December 2000.

\section{Discussion}

Previous epidemiological studies conducted in French Polynesia showed that the sustained transmission of a predominant DENV serotype follows a periodic cycle of 12 years for DENV-1 and ca 20 years for the three other serotypes. Because the islands' population is small and there is little migration, it has been suggested that this time period is necessary to renew the proportion of non-immune hosts [7]. The absence of DENV-2 circulation during the past 16 years, together with the results of a serosurvey conducted in blood donors in 2011-13 that showed a lower level of herd immunity against DENV-2 than the other DENV serotypes [14], highlight the risk for a large DENV-2 outbreak in French Polynesia.

DENV-2 is currently circulating in several PICTs including American Samoa, Fiji, New Caledonia, Palau, Solomon Islands and Vanuatu. Several DENV outbreaks in French
Polynesia resulted from the importation of viral strains from other PICTs, e.g. DENV-4 in 2009 [6] and DENV-1 in 2013 [15]. Frequent tourist exchanges and sporting, cultural and religious events organised between the PICTs increase the risk of virus introduction into French Polynesia, as illustrated by the detection of DENV-2 infection in three travellers coming from Vanuatu to participate in a soccer contest. Phylogenetic analysis confirmed that the DENV-2 strains isolated from these participants belonged to the same lineage as viral strains isolated in other PICTs (Tuvalu and Fiji) in 2014. Although no subsequent autochthonous DENV-2 infections have been detected so far, the occurrence of an outbreak in the coming weeks or months cannot be excluded. In January 2009, two imported DENV-4 infections were detected in inhabitants of French Polynesia returning from New Caledonia where an epidemic had just started [6]. Despite increased surveillance by the French Polynesia Direction of Health and the reinforcement of vector control measures by the Public Health and Hygiene Department, a DENV-4 outbreak was declared 2 months later. 


\section{FIGURE 2}

Phylogenetic analysis of DENV-2 strains isolated in French Polynesia, February 2017 (n = 3)

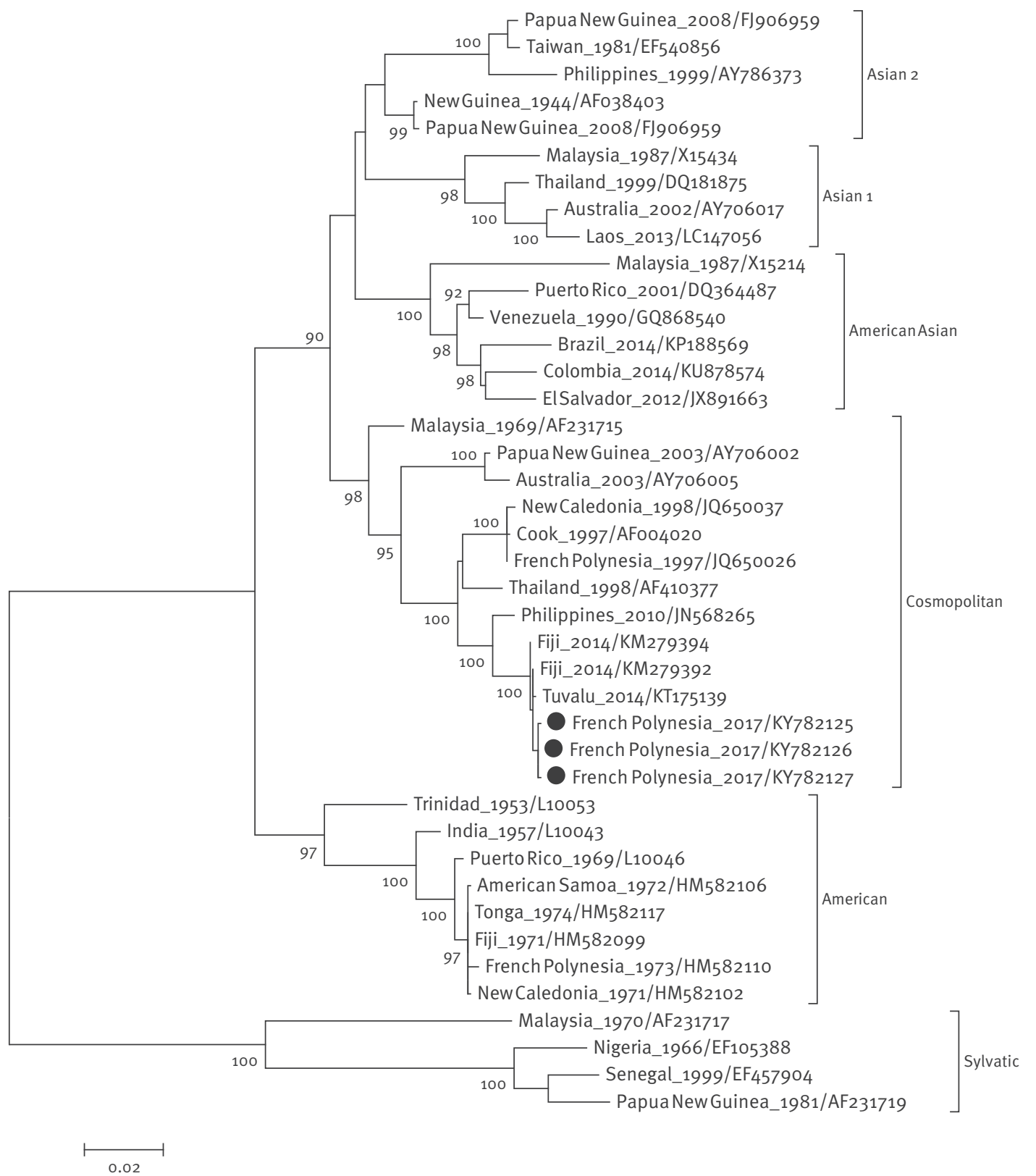

DENV: dengue virus.

The evolutionary history was inferred by using the maximum likelihood method based on the Kimura 2-parameter model [24]. The percentage of trees in which the associated taxa clustered together is shown for values higher than 90 next to the branches (1,00o replicates).

Evolutionary analyses were conducted in MEGA7 [25]. Each strain is labelled by country date of origin / GenBank accession number. The DENV-2 strains isolated in French Polynesia in February 2017 are marked with a black circle

Due to the combination of risk factors exposed above, the occurrence of a new DENV-2 outbreak is to be expected in French Polynesia. Strengthened surveillance measures apply to travellers arriving from countries where DENV-2 is circulating: serotype-specific diagnosis is requested for any suspicion of DENV infection; travellers arriving from New Caledonia, Cook Islands and New Zealand (the transit hub for most PICTs) are informed at arrival about the risk of DENV-2 importation into French Polynesia (awareness-raising flyers, television spots and posters).

Populations of the PICTs have suffered severely from outbreaks of arthropod-borne virus (arbovirus) infections during the past 3 years $[10,16,17]$. Surveillance is a key factor to anticipate and possibly prevent the spread of arboviruses between the PICTs. Effective surveillance requires timely and reliable data sharing on arbovirus circulation in the region; these data are 


\section{FIGURE 3}

The circulation of the four dengue virus serotypes and of Zika and chikungunya viruses in French Polynesia, 1944-2017

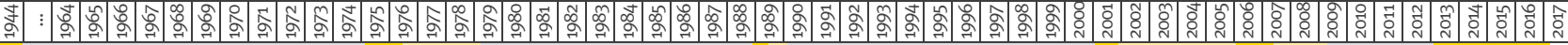

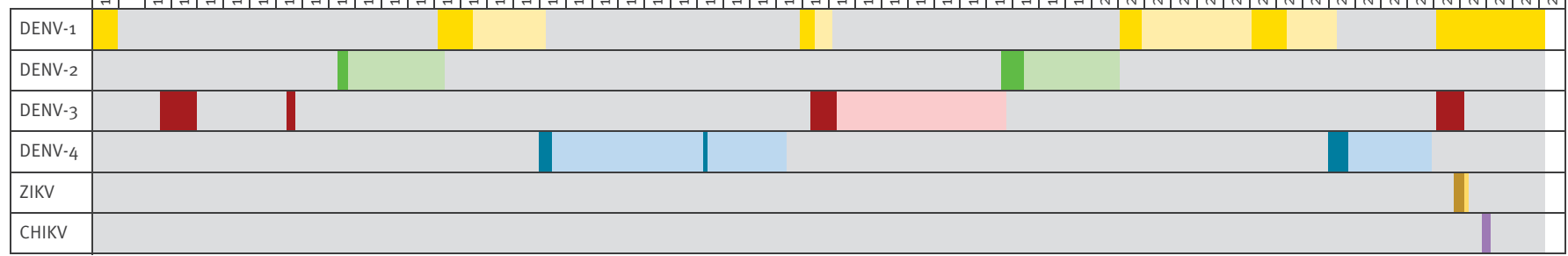

CHIKV: chikungunya virus; DENV: dengue virus; ZIKV: Zika virus.

Bright colours indicate epidemic periods and pale colours indicate inter-epidemic periods with presence of circulating virus.

Epidemic periods in French Polynesia are defined by the detection of a minimum of 10 positive dengue cases per week during at least two consecutive weeks.

Source $[4-10,13]$;

therefore made available and frequently updated by the Pacific Public Health Surveillance Network (https:// www.pphsn.net/). Such information should also be of international interest. Indeed, as recently illustrated with ZIKV, large outbreaks caused by emerging arboviruses in the PICTs can result in virus importation and further autochthonous transmission in non-endemic countries, e.g. in Europe and the Americas [17,18]. Autochthonous transmission of DENV in Europe and North America has already been reported [19-23]. The occurrence of a DENV-2 outbreak in the coming months in French Polynesia would increase the risk of virus importation into such non-endemic countries, particularly mainland France, during the most favourable season for vector-borne transmission.

\section{Erratum}

The authors first and last names were originally published in the wrong order. This was corrected on 7 April 2017. We apologise for the mistake.

\section{Acknowledgements}

The present work received support from the French Ministry for Foreign and European Affairs under the Pacific Funds for ISID-Pacific project (Grant Agreements No. 06314-090414, No. 12115-020915, No. 03016-200516) and support from the European Commission FP7 Programme for the DENFREE project (Grant Agreement no. 282 378FP7).

\section{Conflict of interest}

None declared.

\section{Authors' contributions}

Maite Aubry (MA), Yoann Teissier (YT), Didier Musso (DM), and Van-Mai Cao-Lormeau (VM CL) wrote the manuscript.
Anita Teissier (AT) performed laboratory testing and conducted phylogenetic analyses. Mapotoeke Mihiau (MM) and Marine Giard (MG) conducted the investigations of DENV-2 imported cases.

\section{References}

1. Epidemic and emerging disease alerts in the Pacific region. Noumea: Pacific Community. [Accessed Mar 2017]. Available from: http://www.spc.int/phd/epidemics/

2. ProMED-mail. Dengue/DHF update (03): Asia, Pacific. 20170320.4913845. 20 Mar 2017. Available from: http://www. promedmail.org/

3. Johnson BW, Russell BJ, Lanciotti RS. Serotype-specific detection of dengue viruses in a fourplex real-time reverse transcriptase PCR assay.J Clin Microbiol. 2005;43(10):4977-83. DOI: $10.1128 / J C M .43 \cdot 10.4977-4983.2005$ PMID: 16207951

4. Singh N, Kiedrzynski T, Lepers C, Benyon EK. Dengue in the Pacific--an update of the current situation.Pac Health Dialog. 2005;12(2):111-9.PMID: 18181502

5. Descloux E, Cao-Lormeau VM, Roche C, De Lamballerie X. Dengue 1 diversity and microevolution, French Polynesia 20012006: connection with epidemiology and clinics.PLoS Negl Trop Dis. 2009;3(8):e493. DOI: 10.1371/journal.pntd.0000493 PMID: 19652703

6. Cao-Lormeau VM, Roche C, Aubry M, Teissier A, Lastere S, Daudens $E$, et al. Recent emergence of dengue virus serotype 4 in French Polynesia results from multiple introductions from other South Pacific Islands. PLoS One. 2011;6(12):e29555. DOI: 10.1371/journal.pone.0029555 PMID: 22216313

7. Cao-Lormeau VM, Roche C, Musso D, Mallet HP, Dalipanda T, Dofai A, et al. Dengue virus type 3, South pacific islands, 2013. Emerg Infect Dis. 2014;20(6):1034-6. DOI: 10.3201/ eid2006.131413 PMID: 24856252

8. Cao-Lormeau VM, Roche C, Teissier A, Robin E, Berry AL, Mallet HP, et al. Zika virus, French polynesia, South pacific, 2013. Emerg Infect Dis. 2014;20(6):1085-6. DOI: 10.3201/ eid2006.140138 PMID: 24856001

9. Aubry M, Teissier A, Roche C, Richard V, Yan AS, Zisou K, et al. Chikungunya outbreak, French Polynesia, 2014. Emerg Infect Dis. 2015;21(4):724-6. DOI: 10.3201/eid2104.141741 PMID: 25811534

10. Cao-Lormeau VM, Musso D. Emerging arboviruses in the Pacific.Lancet. 2014;384(9954):1571-2. DOI: 10.1016/S01406736(14)61977-2 PMID: 25443481

11. Chungue E, Deparis X, Murgue B. Dengue in French Polynesia: major features, surveillance, molecular epidemiology and current situation.Pac Health Dialog. 1998;5(1):154-62.

12. Daudens $E$, Lastère $S$, Hirschauer $C$, Cao-Lormeau VM, Louette R, Roche C, et al. Epidemiology of dengue and control strategies in French Polynesia from 2006 to 2008. Bulletin épidémiologique hebdomadaire. 2009;48-49-50:499-503. 
Available from: http://invs.santepubliquefrance.fr beh/2009/48_49_50/beh_48_48_50_2009.pdf

13. Bulletins de surveillance sanitaire en Polynésie française et documents associés. [Health surveillance bulletins in French Polynesia and related documents]. Papeete: Centre d'Hygiène et de Salubrité Publique de Polynésie française. [Accessed Mar 2017]. French. Available from: http://www.hygiene-publique. gov.pf/spip.php?article120

14. Aubry M, Finke J, Teissier A, Roche C, Broult J, Paulous S, et al. Seroprevalence of arboviruses among blood donors in French Polynesia, 2011-2013. Int J Infect Dis. 2015;41:11-2. DOI: 10.1016/j.ijid.2015.10.005 PMID: 26482390

15. Dupont-Rouzeyrol M, Aubry M, O'Connor O, Roche C, Gourinat AC, Guigon A, et al. Epidemiological and molecular features of dengue virus type-1 in New Caledonia, South Pacific, 20012013. Virol J. 2014;11(1):61. DOI: 10.1186/1743-422X-11-61 PMID: 24684835

16. Musso D, Cao-Lormeau VM, Gubler DJ. Zika virus: following the path of dengue and chikungunya? Lancet. 2015;386(9990):2434. DOI: 10.1016/S0140-6736(15)61273-9 PMID: 26194519

17. Roth A, Mercier A, Lepers C, Hoy D, Duituturaga S, Benyon $E$, et al. Concurrent outbreaks of dengue, chikungunya and Zika virus infections - an unprecedented epidemic wave of mosquito-borne viruses in the Pacific 2012-2014. Euro Surveill. 2014;19(41):20929. DOI: 10.2807/1560-7917. ES2014.19.41.20929 PMID: 25345518

18. Cao-Lormeau V-M. Tropical Islands as New Hubs for Emerging Arboviruses.Emerg Infect Dis. 2016;22(5):913-5. DOI: 10.3201/ eid2205.150547 PMID: 27088243

19. Succo T, Leparc-Goffart I, Ferré JB, Roiz D, Broche B, Maquart $M$, et al. Autochthonous dengue outbreak in Nîmes, South of France, July to September 2015. Euro Surveill. 2016;21(21):30240. . Available from: Autochthonous dengue outbreak in Nîmes, South of France, July to September 2015 DOI: 10.2807/1560-7917.ES.2016.21.21.30240 PMID: 27254729

20. Gjenero-Margan I, Aleraj B, Krajcar D, Lesnikar V, Klobučar A, Pem-Novosel I, et al. Autochthonous dengue fever in Croatia, August-September 2010. Euro Surveill. 2011;16(9):19805. Available from: Autochthonous dengue fever in Croatia, August-September 2010.PMID: 21392489

21. Tomasello D, Schlagenhauf P. Chikungunya and dengue autochthonous cases in Europe, 2007-2012.Travel Med Infect Dis. 2013;11(5):274-84. . Available from: Chikungunya and dengue autochthonous cases in Europe, 2007-2012.DOI: 10.1016/j.tmaid.2013.07.006 PMID: 23962447

22. Murray KO, Rodriguez LF, Herrington E, Kharat V, Vasilakis $\mathrm{N}$, Walker $\mathrm{C}$, et al. Identification of dengue fever cases in Houston, Texas, with evidence of autochthonous transmission between 2003 and 2005 . Vector Borne Zoonotic Dis. 2013;13(12):835-45. Available from: Identification of dengue fever cases in Houston, Texas, with evidence of autochthonous transmission between 2003 and 2005.DOI: 10.1089/ vbz.2013.1413 PMID: 24107180

23. Adalja AA, Sell TK, Bouri N, Franco C. Lessons learned during dengue outbreaks in the United States, 2001-2011. Emerg Infect Dis. 2012;18(4):608-14. . Available from: Lessons learned during dengue outbreaks in the United States, 2001-2011.DOI: 10.3201/eid1804.110968 PMID: 22469195

24. Kimura M. A simple method for estimating evolutionary rates of base substitutions through comparative studies of nucleotide sequences.J Mol Evol. 1980;16(2):111-20. DOI: 10.1007/BF01731581 PMID: 7463489

25. Kumar S, Stecher G, Tamura K. MEGA7: Molecular Evolutionary Genetics Analysis Version 7.0 for Bigger Datasets.Mol Biol Evol. 2016;33(7):1870-4. DOI: 10.1093/molbev/msw054 PMID: 27004904

\section{License and copyright}

This is an open-access article distributed under the terms of the Creative Commons Attribution (CC BY 4.0) Licence. You may share and adapt the material, but must give appropriate credit to the source, provide a link to the licence, and indicate if changes were made.

This article is copyright of the authors, 2017. 